\title{
Simulation of an Automatic Meter Reading System for Smart Metering by using ASK/OOK Modulation in Rural Smart Micro-grids
}

\author{
G. Joga Rao ${ }^{1}$, P.Naresh' ${ }^{2}$,G.S.N.M Venkatesh ${ }^{3}$,P.Ramireddy ${ }^{4}$ \\ ${ }^{1}$ Associate Professor, Department of Electrical \& Electronics Engineering \\ Raghu Institute of Technology, Visakhapatnam, India. \\ jogarao.phd@gmail.com \\ ${ }^{2}$ Assistant Professor, Department of Electrical \& Electronics Engineering \\ Raghu Engineering College, Visakhapatnam, India. \\ ${ }^{3}$ Assistant Professor, Department of Electrical \& Electronics Engineering \\ Raghu Institute of Technology, Visakhapatnam, India. \\ ${ }^{4}$ Assistant Professor, Department of Electrical \& Electronics Engineering \\ Kamala Institute of Technology \& Science, Telangana, India.
}

\begin{abstract}
Smart grids are electric power grids that are more efficient and reliable. These are playing an essential role in modern world.Smart grids, which include a variety of operational and energy measures including smart appliances, smart metersand energy efficiency sources. The important aspects of the smart grids are the electrical power conditioning, production control and distribution of electricity. The smarts are not only focused on elimination of black- and brown-outs, but also on making the grid greener and more efficient, and therefore less costly.Now a day theresearch exercise on these smart grids involves the development in the field of Smart Metering.The inexpensiveness, simple and easy to spread out qualities lie in Power Line Communications (PLC) which made them to use in electrical power grids. This paper presents a scheme of Automatic Meter Reading Systems for Smart Metering network with PLC technology using ASK/OOK'S modulationin rural smart micro-grids. PLC with AMR systems used in power delivery system can monitor and record illegal electricity usage by detecting system which may be additionally added in present network.The PLC with AMR Systems can reducethe illegal usage of electricity and theft in rural areas. Fast and Reliable meter reading collection with less error can be achieved with AMR Systems which eliminates the necessity of physically reading the meters.In this paper, the proposed scheme for Smart Metering has been simulated in MATLAB/SIMULINK software and results are presented successfully.
\end{abstract}

Keywords-Automatic Meter Reading (AMR); Smart Micro-Grid; Smart Metering; Amplitude-Shift Keying / On-Off Keying (ASK/OOK) FSK Modulation and Demodulation; Power Line Communication (PLC); MATLAB/SIMULINK.

\section{INTRODUCTION}

Today's the electricity is generated in large power stations and transmitted by interconnected high voltage transmission lines in grid system. Because of nonexistence of effective transmission system problem, a possible power cut on high voltage transmission lines can affect other grids negatively. For these reasons the request for a new network is emerging but it will be used in network communication system will be more important concept. Now a day the recent world uses smart metering broadly that spread out smart meters in the smart grid development by the great support from the factories and utility industries. There are different technologies such as wireless, fiber optic, and power line communication (PLC) is available for the smart grid communication infrastructure [1]. The modern electricity industries and companies are using this PLC technology in various applications. Smart grid systems improve the power quality and reliability of electrical power systems with reduced time delays.

The use of smart metering with PLC is increased day by day which lead to early PLC systems beginning since last decade. Smart metering make use of technology in digital form to increase steadiness, accuracy, safety and electric network productivity from bulk generation, over the distribution networks to electricity consumers and increasing distributed generation and storing capitals. The energy loss and deceit by collecting data of electricity generation from meters and electrical substations cab be detected by AMR. The Automatic meter reading (AMR) technology can be used for the purpose of billing estimation, which automatically collects information from water, gas and energy metering devices and transfers it to the master station. Physically there is no requirement for reading the meter; remotely information can be read easily [2]. The peak demand for energy and 
cost of meter reading can be minimized which enables customers to make informed decisions and thus backup the particular time usage idea for billing. Present day'sdifferent communication technologies like mobile tools, radio frequency, the platforms of telephonic, or the power line communication (wired or wireless) have been used in AMR. Developing a present mobile network for data transmission requires no extra tools or software, resulting in an important savings in bothcapital and time. The significant reduction in the cost of building a new communication network can be achieved by Power Line Carrier (PLC) which make PLC best for AMR systems [3]. The communication and bandwidth is limited, thus the minimum-voltage supply power systems are not made. It can be perfectly suitable for rural/agricultural connections because of using equivalent power lines as communication media.

\section{AUTOMATIC METER READING SYSTEM}

Automatic Meter Reading (AMR) is a technology that automatically collects utilization or consumption data from a water meter or energy metering device. This data is used for billing purposes; to identify or resolve technical problems and to analyze usage and manage consumption. AMR systems promote more apprehensive electricity and water usage by revealing exactly how a site is using resources, and where reductions can be made to improve efficiency and lower costs. AMR continually collects data, and can provide this information on a real-time basis. Usage data can be viewed at any time, and once collected, is immediately stored in a depository of historical consumption data for comparative or analysis purposes.

\section{A. Components of AMR System}

1)Meter Interface Module:At the AMR system, the meter can be well and properly controlled. It is very essential to send digital data from consumer station to main station. It consists of meter interface module with battery backup, electrical power supply, controlling module and communication interface. It allows data to be transmitted from this remote device to a central location.

2) Central Station (Control centre): AMR system has each and every section in the arrangement like reading of meter on monthly basis or inspection of actual position of each and every concentrator involving analysis of error and disturbing can be managed by super capacity computers through the levelled communication network. Furthermore, with the help of interconnection with the power supply system, the tariff calculation and collection can be realized.

3) Electrical Meter: The content of generating electrical energy to domestic or commercial utilities is measured by an electronic device. It consists of electronic controllers which are fed electrically. It acts as a border that transfers information which can be communicated through the source end acting at the collector.

4) Collector: Based on the signal of the concentrator which is in upper position, collector will collect and develop the information which is received from several meters of electrical utility industry or company. It has the ability to forward, enhance and giving out information needed by the concentrator. The collector has to do the controlling of smart electrical meters which are found in precise usages.

5) Concentrator: The commands are to be given by the concentrator which can be fed to collector for receiving readings of electrical meter occasionally like weekly or monthly basis. For an advance analysis, load survey data and meter readings can be transmitted to the database of main control station. 
The AMR Architecture as shown in Fig.1 below.

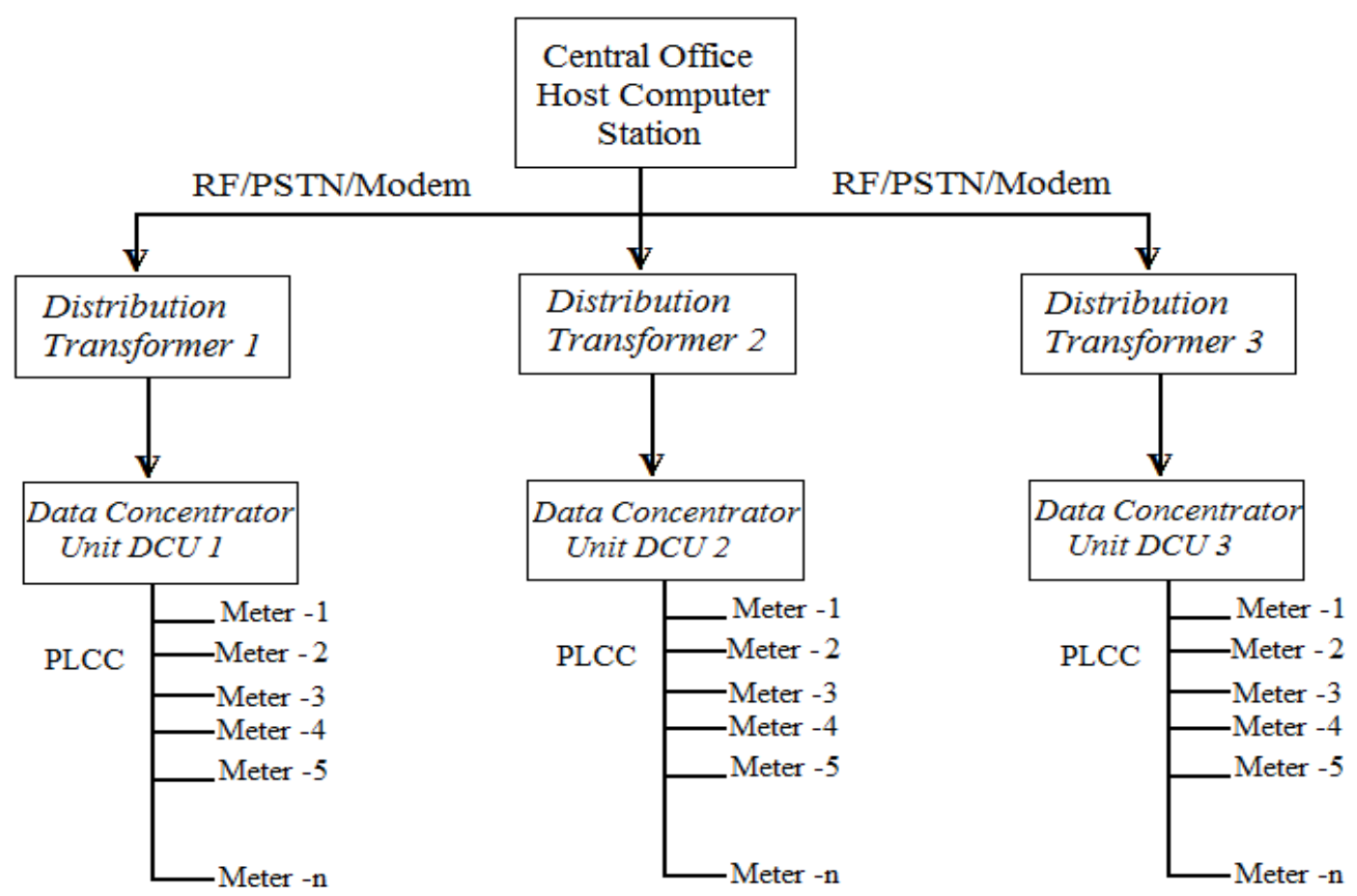

Fig.1. AMR Architecture

\section{B. PLCC Communication in AMR System}

Power Line Carrier Communication is a system for carrying data on a conductor. It also used for electrical power transmission. Most of the PLCC technologies limit themselves to one set of wires (premises wiring), but some can cross between two levels (both the distribution network and premises wiring). Mostly the transformer restricts the propagating signal so multiple PLCC technologies are bridged to form big networks. The PLCC that enables transferring data over AC power wiring. So there is no need to any additional wiring for communication network. [4]. This is obtained by adding a high frequency signal at low energy levels over the electric signal and the second signal is propagated through the power network to the receiving end [5]. The implementation of Smart Micro-grid using basic block diagram of ASK/OOK shown in Fig.2. Developing information server to access several links of PLC for convenient controlling of swapping information between intelligent micro-grid and consumers. The customary grid is an intelligent digital version involving improved technologies of communication and calculation. Domestic utilities and intelligent meters are combined with HAN (Home Area Network) device coordinator as shown in Fig.2. With the help of Power Line Carrier Modem and linking circuit, Smart meter and Smart micro-grid are combined. HAN system of network swapping information between each and every domestic utilities and power line communication network. So with the help of Power line communication system, the companies will have the ability to combine not only the intelligent meters but also current domestic electrical utilities [6]. Power Line Communication system has the ability to communicate in two ways and existing extensively. So in the absence of other communication system, power line communication system can be well adapted in slum zones and optimizing cost problems to exchange information between consumers and electrical utility companies. The PLC Communication in AMR is shown in Fig.3. The secondary winding of the distribution transformer contains data concentrator. The complete setup contains the modem system. Power line receives the data obtained by modulation and demodulation which is done by ASK/OOK modem. The total system follows the ASK/OOK modulation technique. Transmission and receiving of data and vice versa is done by the modem by placing at the consumer as well as utility side. The method used for the power line transfer is Serial communication. Power Line Communication System can be used to gather meter readings from all the meters with the help of serial communication method at predefined breaks. A subsystem of Host Computer Station (HCS) consists of Data Concentrator Unit (DCU) and every meter connecting to it. The power zone in low voltage downstream of a Distribution Transformer can be controlled by DCU Subsystem setup as shown in Fig.1. The noticing outages, tamper events and performing remote disconnect can be done by PLCC in 440V LT network. It can be perfectly suitable for rural/agricultural connections because of using equivalent power lines as communication media. The implementation of HT side communication can be done through the best of GSM, CDMA, PSTN or RF as shown in Fig.3. The conversion of electronic Energy Meters CF pulses into Electrical pulses can be done by PLC unit which consists of a single 
PCB. The displaying of meter reading and collection of electrical pulses can be done by Microprocessor [7] which in turn converts this data into Power Line Modulation. Before Retrofit is made into operation, the Meter Constant, Current Meter reading and Meter ID are accumulated in Micro Controller NV RAM. The pulses equal to Meter constant which can be sensed by Retrofit then one unit is incremented which is stored in Micro Controller NV RAM.

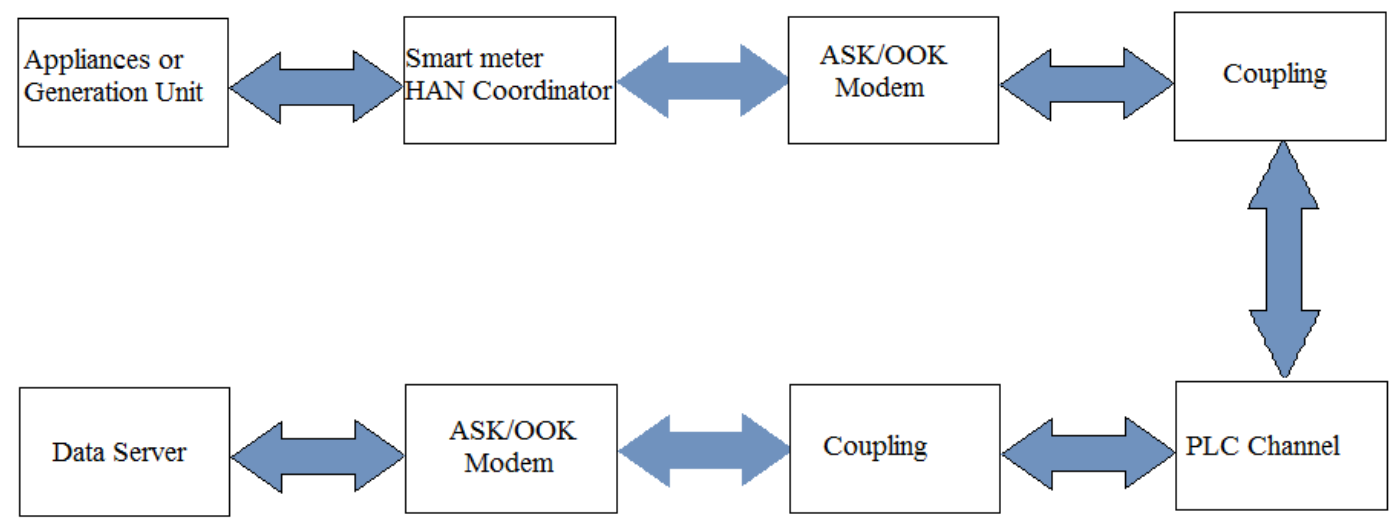

Fig.2.Implementation of Smart Micro-grid using basic block diagram of QPSK

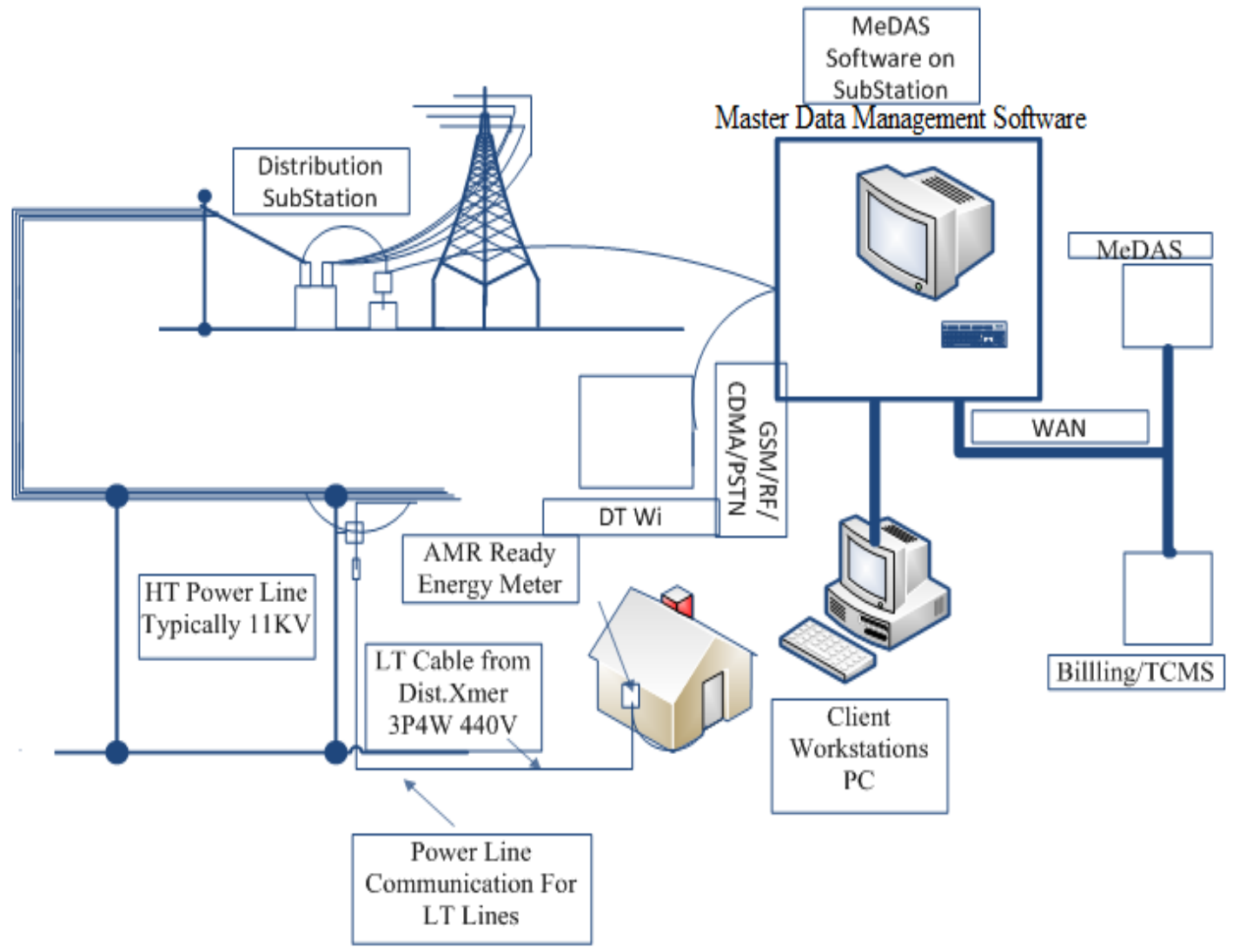

Fig.3. PLCC Communication in AMR

\section{POWER LINE CHARACTERIZATION AND MODELING}

Power Line network is not initially designed to carry information. But educed operation and management with initial cost expenditures. However due to the presence of numerous elements on a power line network, signal attenuation is likely to be an issue and the greater amount of electrical noise on the line limits practical transmission speed. The home appliances like the vacuum cleaners, light dimmers and drills are examples of noise sources that influence the performance of a power line communication based home network. [8]. Distance is another issue that affects the power line communication performance [9]. If the signal attenuation and noise problems of PLC will be minimized, then this is the most appropriate method. The parameters of resistance, inductance, capacitance and conductance must be measured for characterization and modeling of 
communication channel. According to the line theory of pair power cable of surge impedance and propagation constant can be estimated by following equations.

$$
\begin{gathered}
Z_{L}=\sqrt{\frac{R+j \omega L}{G+j \omega C}}(1) \\
\gamma=\sqrt{(R+j \omega L)(G+j \omega C)}(2)
\end{gathered}
$$

Where,

$$
\begin{aligned}
& Z_{L}=\text { Characteristic impedance } \\
& \mathrm{R}=\text { unit length resistance } \\
& \mathrm{L}=\text { unit length inductance } \\
& \mathrm{G}=\text { unit length conductance } \\
& \alpha=\text { attenuation constant } \\
& \beta=\text { phase constant } \\
& \gamma=\text { propagation constant } \\
& \omega=\text { angular frequency }
\end{aligned}
$$

The characteristic impedance and propagation constant depend on R, L, G and angular frequency but not length of line.

\section{A. Design of ASK/OOK Modem with PLC Channel}

The fundamental aim of modulation is to squeeze as much data into the least amount of spectrum possible. That objective, called as spectral efficiency. This measures how rapidly data can be transmitted in an allowed bandwidth. Multiple techniques have developed to attain and improve the efficiency. There are three basic ways to modulate a sinusoidal wave radio carrier such as modifying the amplitude, phase and frequency. In order to increase the spectral efficiency more sophisticated methods combine two or more of these variations.Modulation in a digital is a procedure which moves a character which is in digital form having indicator appropriate to receive indication at destination end for held together communication or unbounded stage of communication without having data leakage. The modulated signal bandwidth is based on band signal and modulation pattern needed. Characters in digital form order are needed for high frequency carrier signal. Phase Shift Keying (PSK), Frequency Shift Keying (FSK) and Amplitude Shift Keying (ASK) are the three main types of modulation in digital. The combination of two orthogonal Binary Phase Shift Keying (BPSK) modulated signals from Quadrature Phase Shift Keying (QPSK) [10], [11].

The Amplitude Shift Keying(ASK) is a simplest modulation method, where a binary information signal directlymodulates the amplitude of an analog carrier.Thisis similar to standard amplitude modulation exceptthere are only two output amplitudes possible. ASK sometimes called as digital- amplitudemodulation(DAM).ASK mathematically represented as

$$
S(t)=\left[1+v_{m}(t)\right]\left[\frac{A}{2} \cos \left(\omega_{c} t\right)\right](3)
$$

Where

$S(t)=$ Amplitude shift keying wave

$v_{m}(t)=$ modulating digital information signal in (volts)

$\mathrm{A} / 2=$ un-modulated carrier amplitude in volts

$\omega_{\mathrm{c}}=$ analog carrier radian frequency $\left(2 \pi \mathrm{f}_{\mathrm{c}} \mathrm{t}\right.$ radians / second $)$

In Equation (3), the modulating signal $v_{m}(t)$ is a normalized binary waveform, where $+1 \mathrm{~V}$ represents logic 1 and $-1 \mathrm{~V}$ represents logic 0 . Therefore $S(\mathrm{t})$ can be written as (4) and (5) for logic 1 input, $v_{m}(t)=+1 \mathrm{~V}$ and for a logic 0 input, $v_{m}(t)=-1 \mathrm{~V}$ respectively.

$$
\begin{gathered}
S(t)=[1+1]\left[\frac{A}{2} \cos \left(\omega_{c} t\right)\right]=\frac{A}{2} \cos \left(\omega_{c} t\right)(4) \\
S(t)=[1-1]\left[\frac{A}{2} \cos \left(\omega_{c} t\right)\right]=0(5)
\end{gathered}
$$

Thus, the modulated wave $S(t)$, is either $A \cos \left(\omega_{c} t\right)$ or 0 for logic input 1 and logic input 0 respectively. Hence, the carrier signal is either 'on' or 'off' therefore, sometimesamplitude-shift keying is referred to as OnOffKeying(OOK). Fig.4 shows the input and output waveforms from ASK /OOK modulator. 


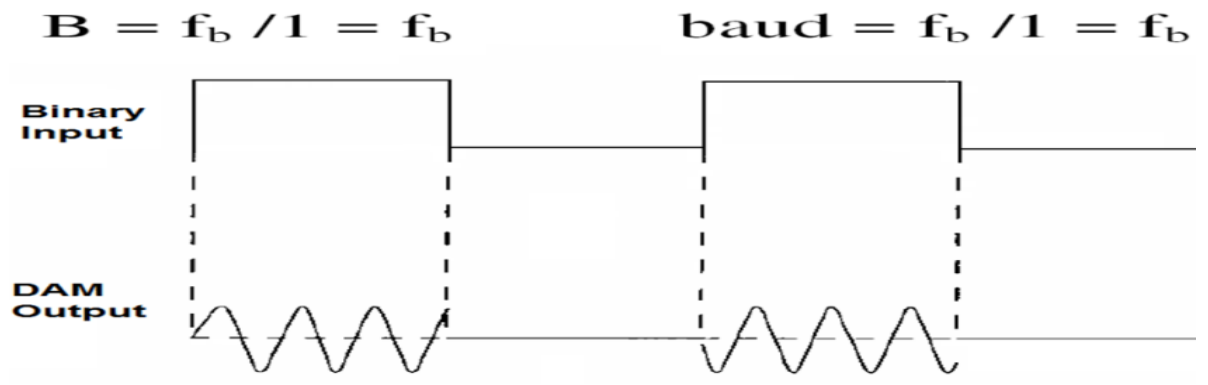

Fig.4. ASK/OOK Modulator binary input and output

Binary zero and binary one can be well indicated in absence and presence of a carrier for a particular duration in its modest form. The OOK/ASK Modulation system is the base structure of wired and wireless communication such as wired modem, 3G,WiMAX and Wi-Fi. These techniques have the advantage of optimizing the bandwidth use of OOK/ASK system which is highly useful in communication technology. Information bits are gathered into pair and specific waveforms is indicated by respective pair called symbol or character in OOK/ASK method. The ASK/OOK Modulation output with mathematical equations are described in the Fig.5. With the help of two carriers in the concept of constellation diagram the amplitude and phase of a signal can be determined. The concept of constellation diagram of ASK/OOK is shown in Fig.6. A constellation diagram helps to illustrate the amplitude and phase of a signal. The X-axis and Y-axis represents the in-phase carrier and quadrature carrier respectively. The block diagram of ASK/OOK Modulator is shown in Fig.7. The binary bits of information signal are separated to I bits and Q bits by serial to parallel converter at input modulator. ASK/OOK signal of binary data is added to modulated signal over I and Q channels [12], [13], [14]. Dual modulators output is connected by summer amplifier, that results ASK/OOK modulator modulated signal. The basic block diagram of ASK/OOK Demodulator as shown in Fig.8. The signal modulated in digital form is given to ASK/OOK Demodulator. In coherent detection technique, receiver is suppressed carrier signal which involves several performance considerations. In demodulator received signal is multiplied by reference frequency generators. Non-return-to-zero (NRZ) converter block and synchronized bits have the information categories phase (I) and quadrature phase (Q) extracted by Multipliers which are low pass filtered.

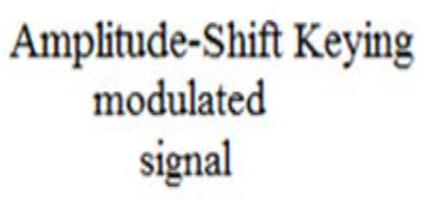

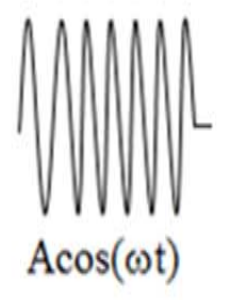

Modulation

$$
\begin{aligned}
& \text { "1" } \longrightarrow s_{1}(t)=\sqrt{\frac{2 E}{T_{b}}} \cos \left(2 \pi f_{c} t\right) \\
& \text { "0" } \longrightarrow s_{2}(t)=0 \quad 0 \leq t<T_{b}
\end{aligned}
$$

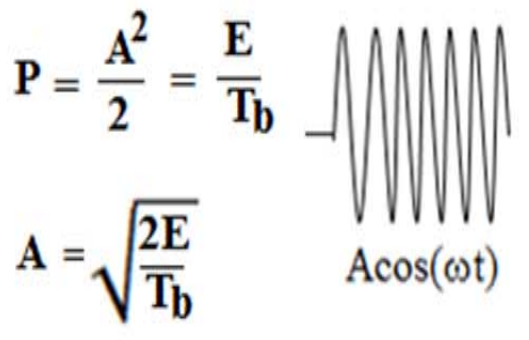

Fig.5. ASK/OOK Modulation output with mathematical equations

The signal modulated in digital form is given to ASK/OOK Demodulator. In coherent detection technique, receiver is suppressed carrier signal which involves several performance considerations. In demodulator received signal is multiplied by reference frequency generators. Non-return-to-zero (NRZ) converter block and synchronized bits have the information categories phase (I) and quadrature phase (Q) extracted by Multipliers which are low pass filtered. 

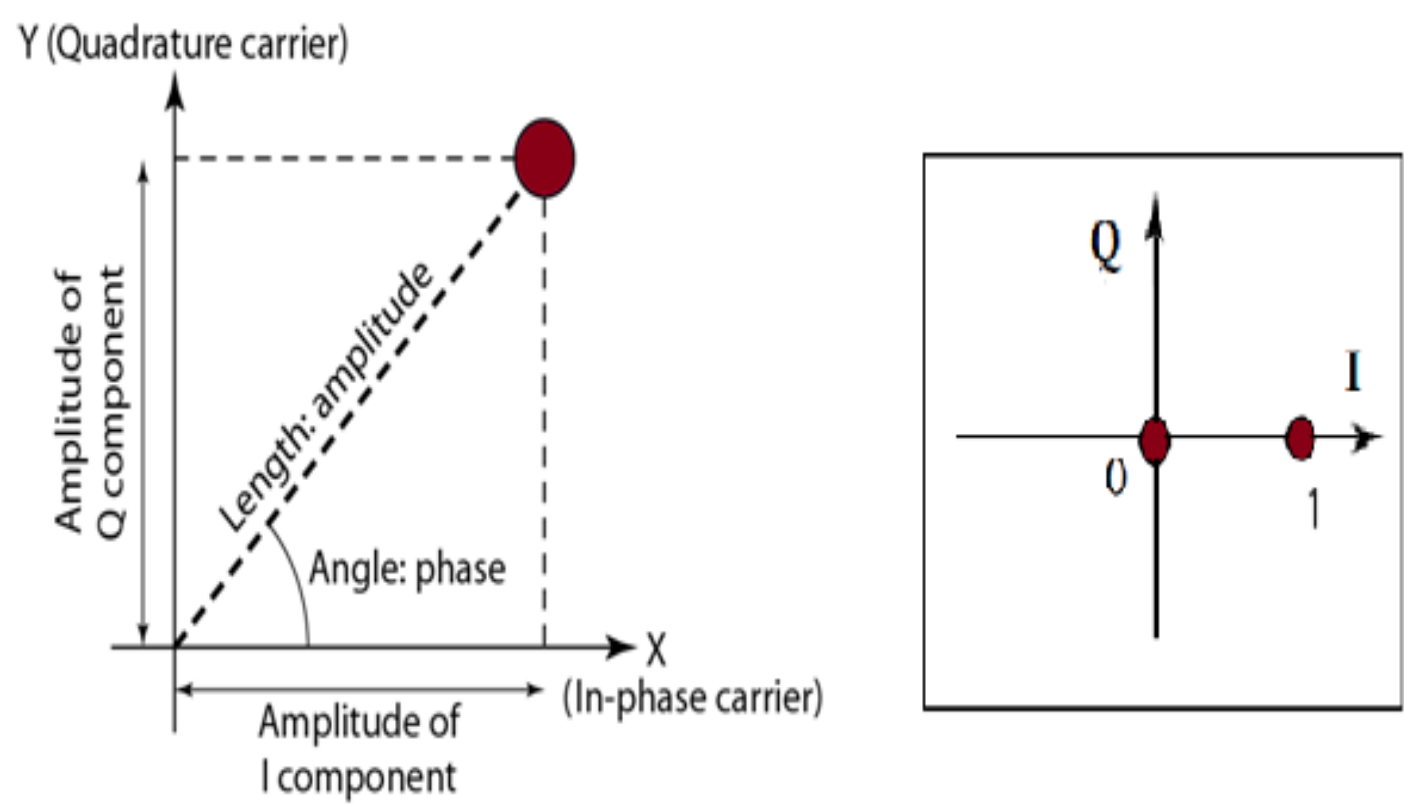

Fig.6. Concept of Constellation diagram of OOK/ASK

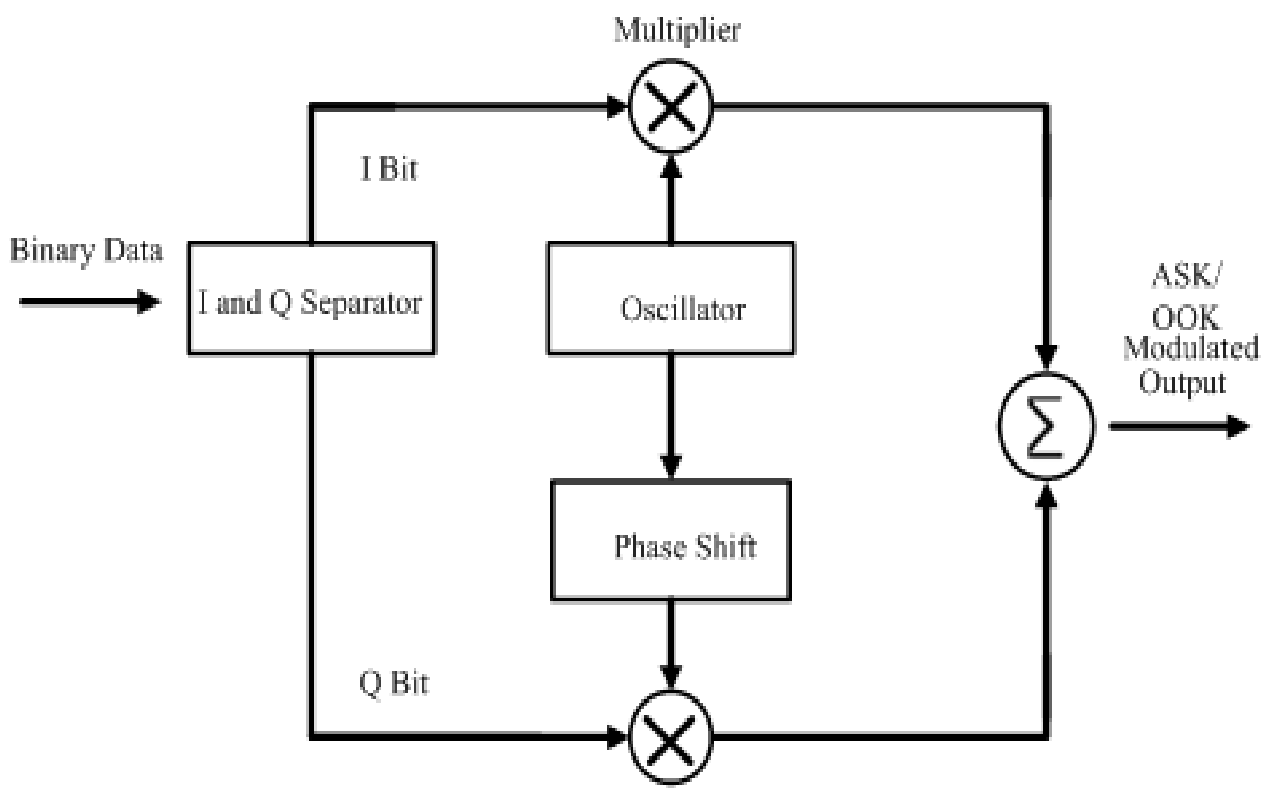

Multiplier

Fig.7. Block Diagram of ASK/OOK Modulator 


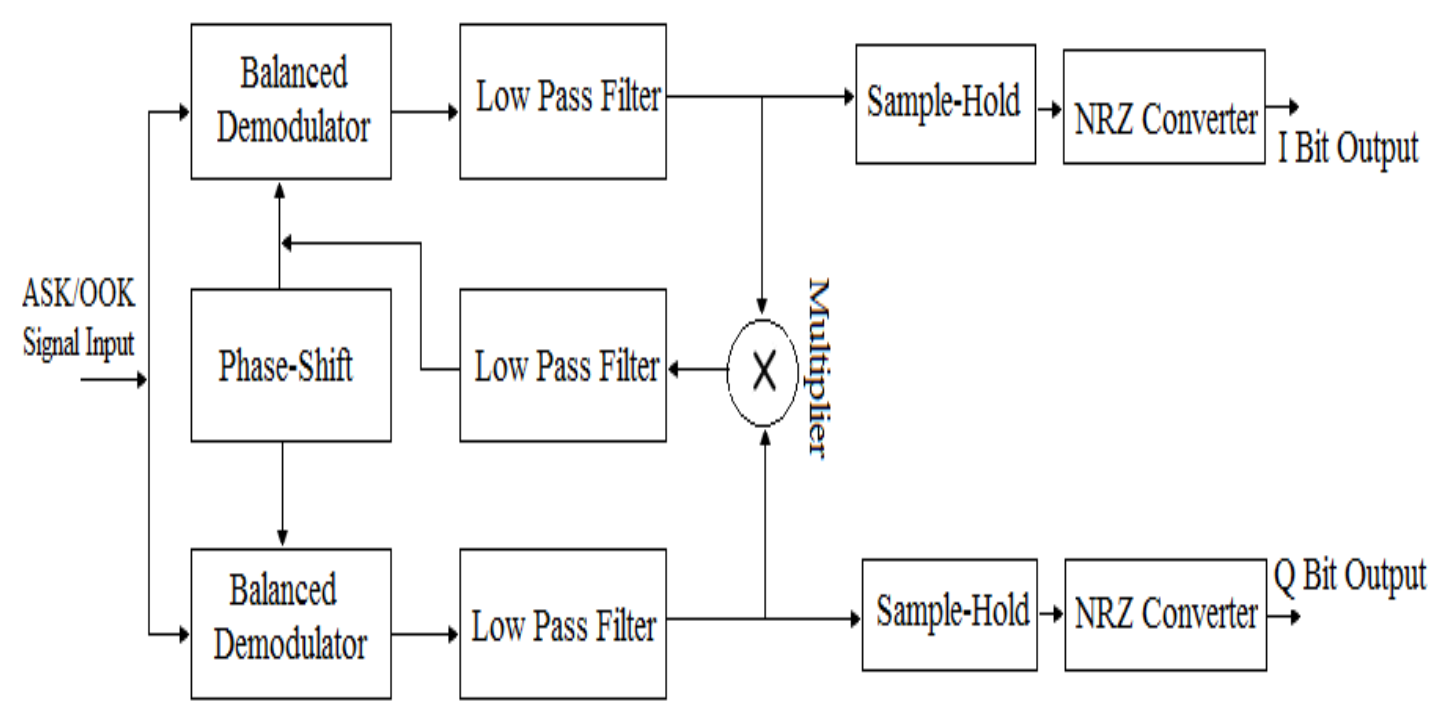

Fig.8. Block Diagram of ASK/OOK Demodulator

\section{SIMULATION RESULT OF THE PROPOSED MODEL}

The simplified block diagram of the PLC network with ASK/OOK modem for intelligent micro grid as shown in Fig.9. The simulation diagram in MATLAB/Simulink of proposed model with ASK/OOK modem is shown in Fig10. For simulation in multi-path with multiple data propagation purpose, we have considered three Bernoulli Binary generator block tools box as a sources of digital signal of three smart meters. The power measurement information of smart meter is supplied to modulator part of ASK/OOK modem and that signal feed to distribution line by coupling circuit. Distribution line is depicted for each phase with fixed line impedance parameters. Estimation and realization of power line communication method can be done in energy and communication analysis. The information modulated for the three inputs are designated as the resultant power information to three smart meters. Modulated I signal and Q signal are added at output modulator. The simulation results of ASK/OOK Modulator is shown in Fig.11 and Fig.12. The Demodulator of ASK/OOK have the modulated signal input and the input which is in digital form is equivalent to the demodulated signal. On the side of demodulation, the resultant demodulated signal is free from phase (I) and Quadrature phase (Q) channels output. The simulation results of ASK/OOK Demodulator is shown in Fig.13 and Fig.14. The Data In and Data Out bits With ASK/OOK have the simulation results shown in Fig.15 and Fig.16.

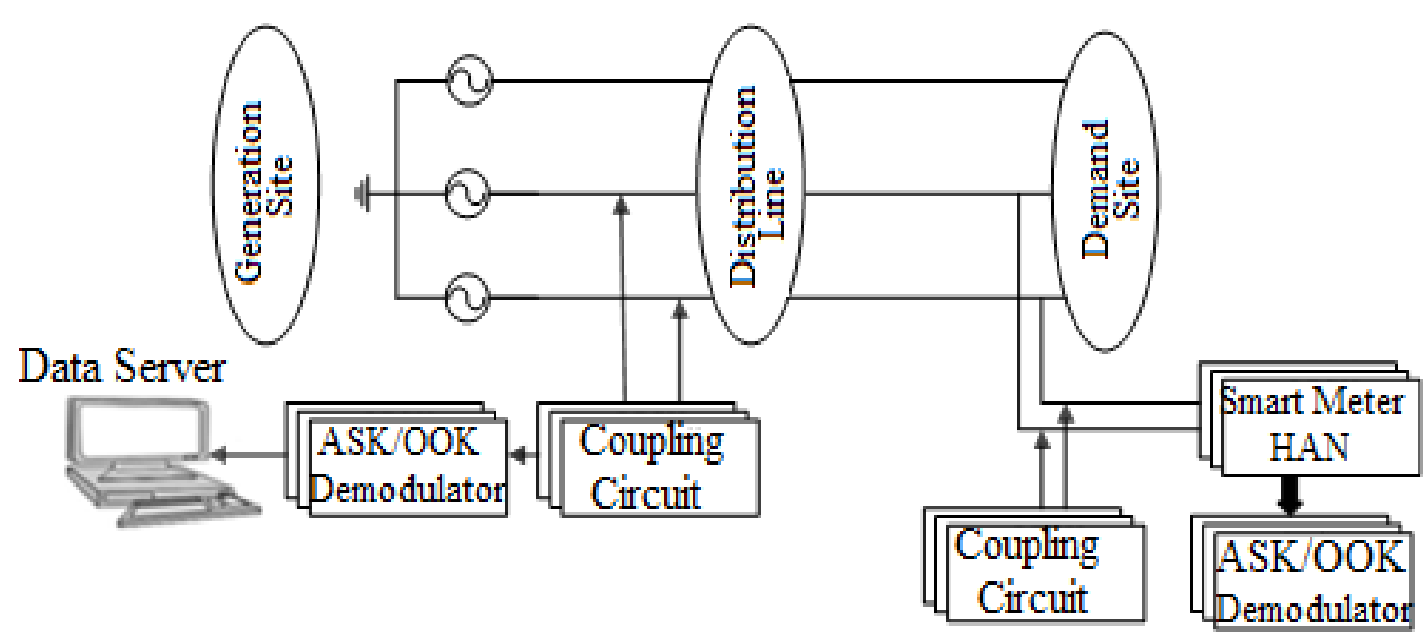

Fig.9. Simplified Diagram of PLC Network with ASK/OOK Modem for Smart Micro-Grid 


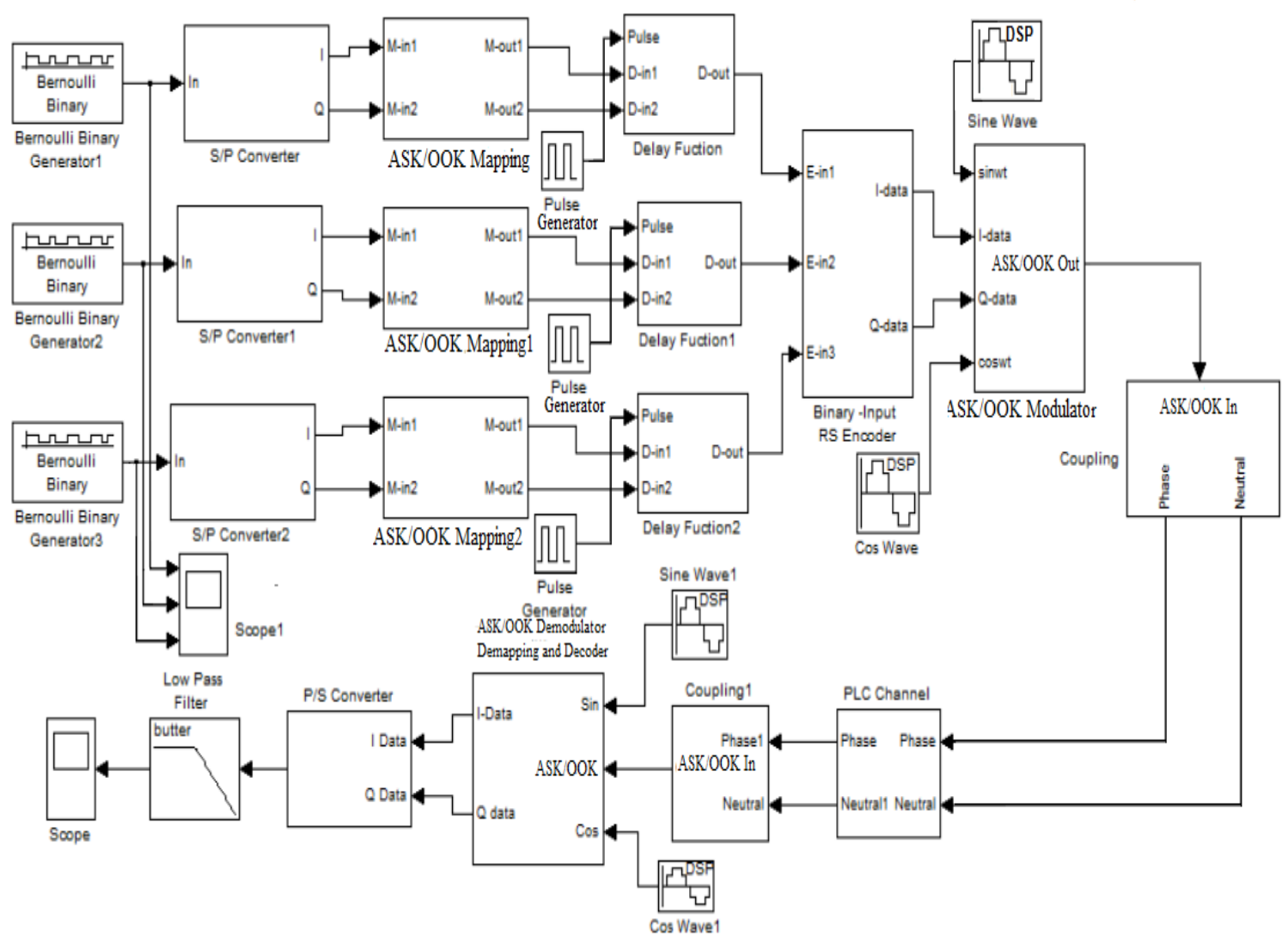

Fig.10. ASK/OOK Modem with PLC Channel for Data Propagation in MATLAB/Simulink
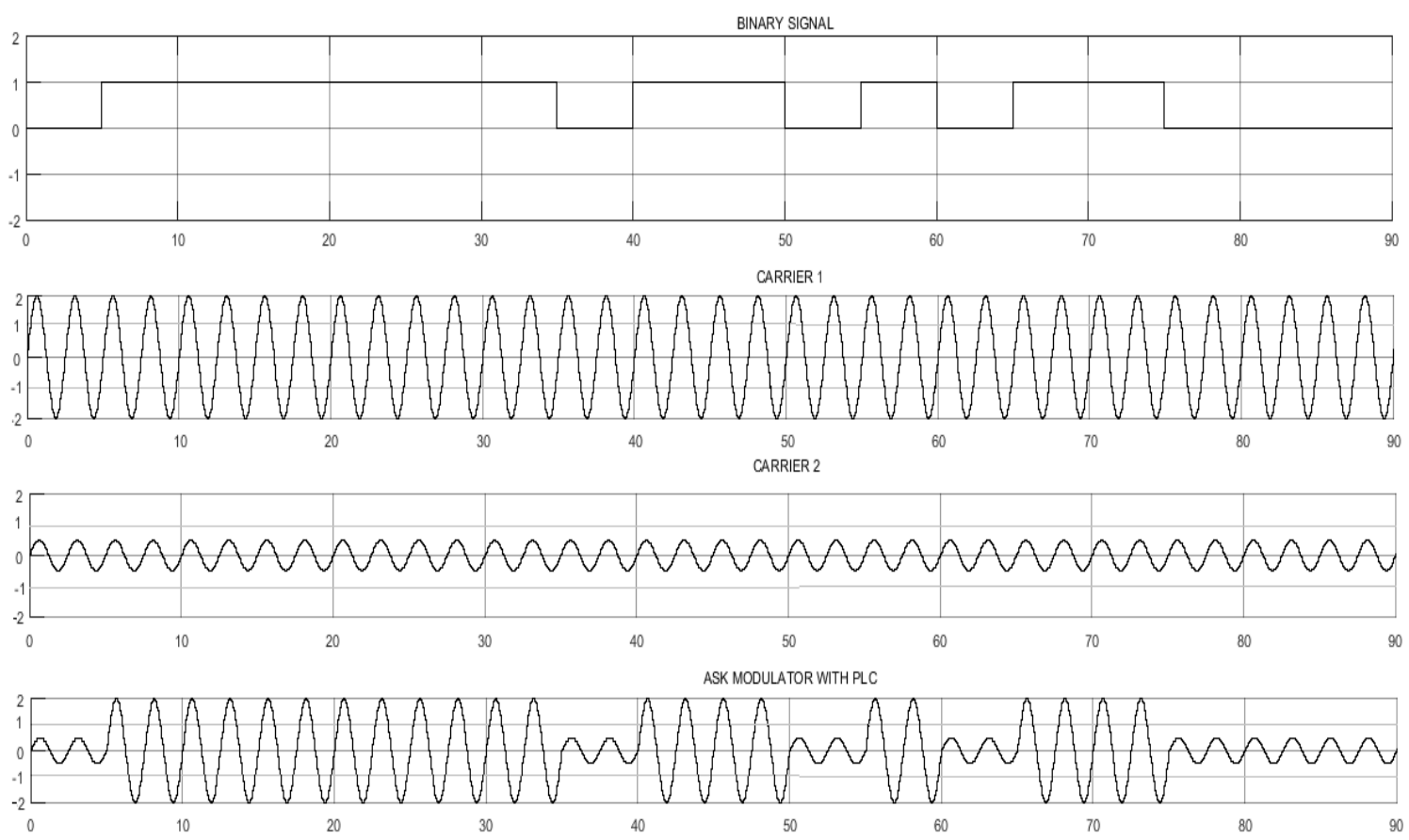

Fig.11. Simulation Result of ASK Modulator with PLC 

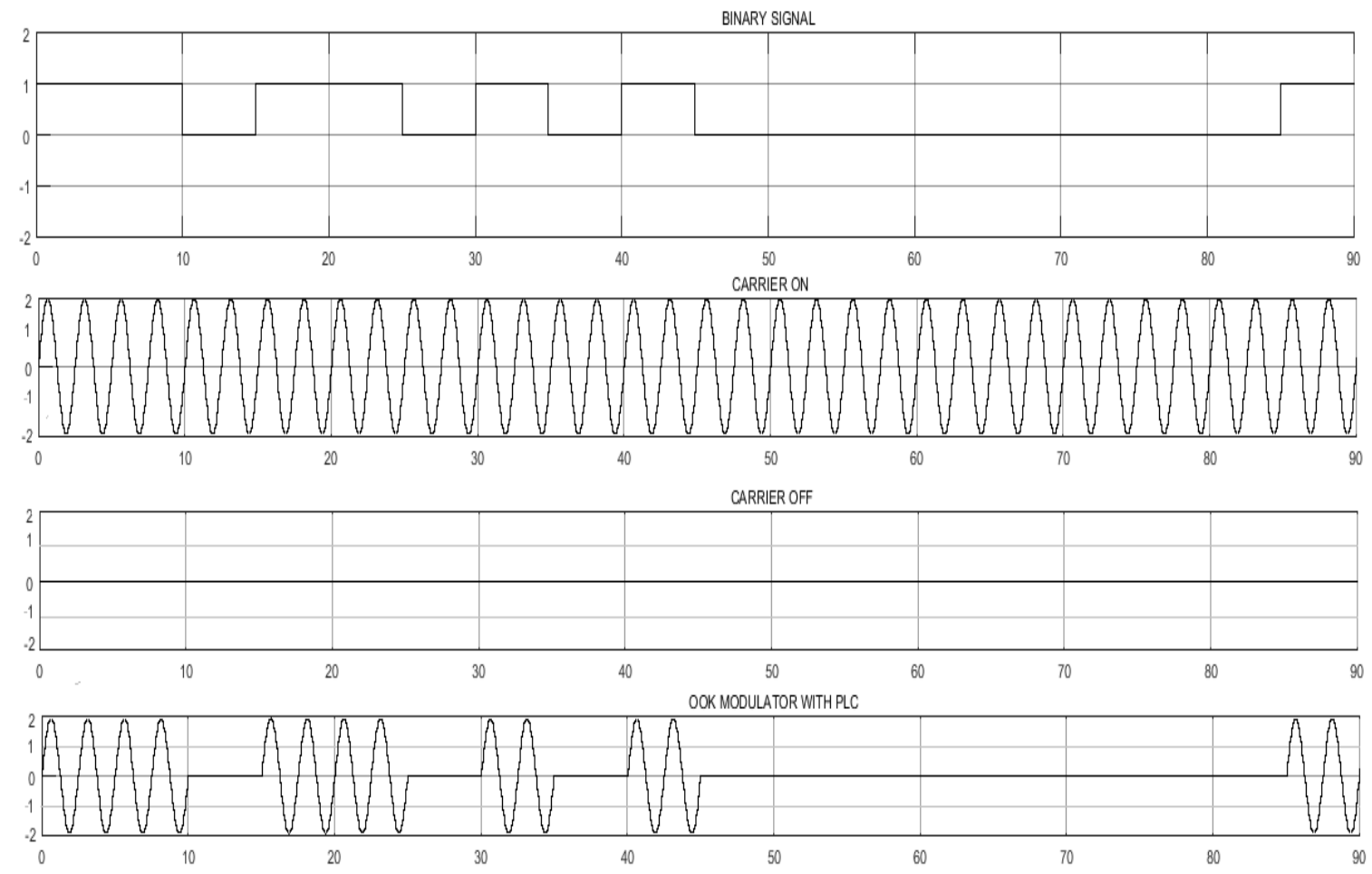

Fig.12. Simulation Result of OOK Modulator with PLC
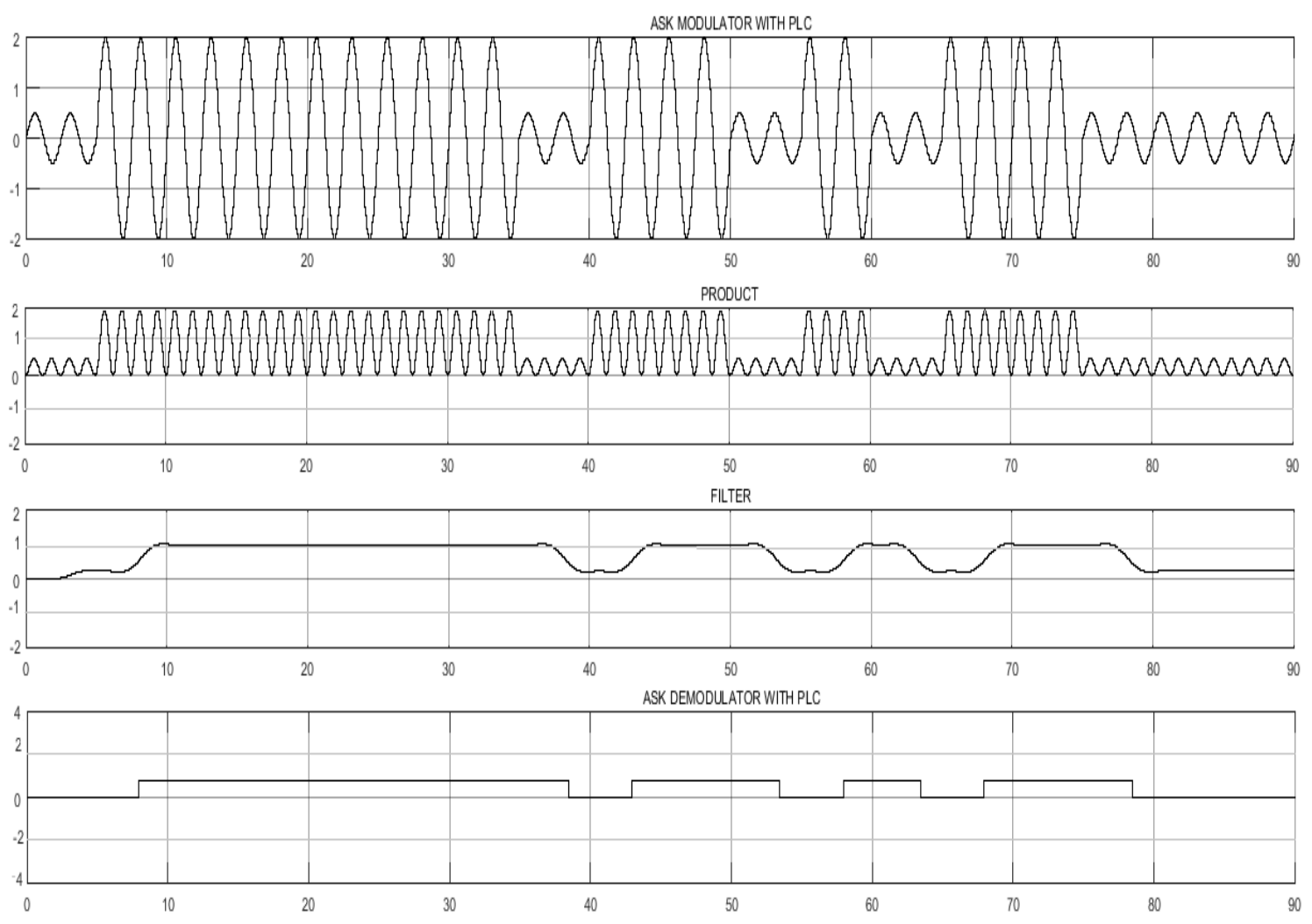

Fig.13. Simulation Result of ASK Demodulator with PLC 

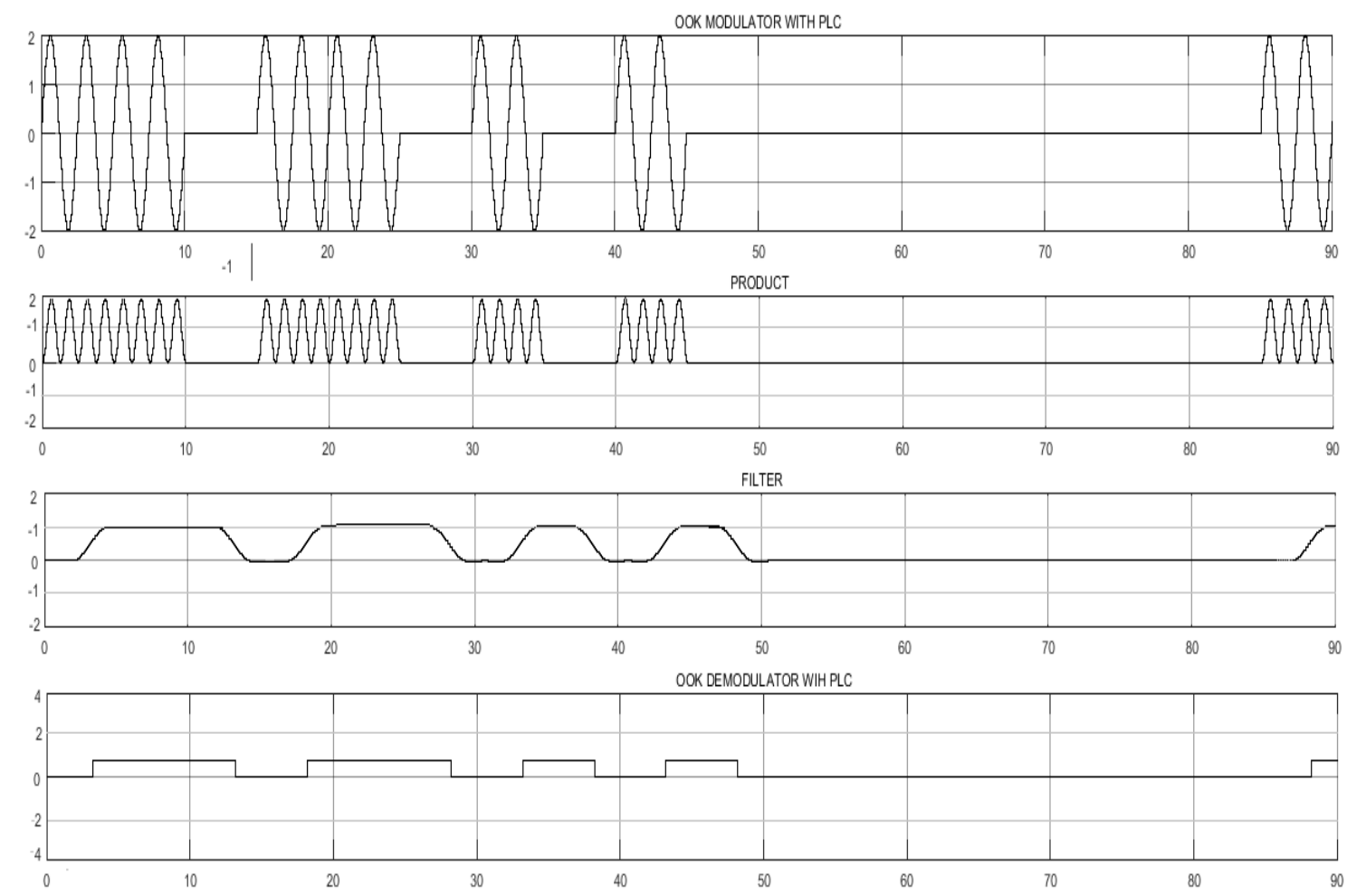

Fig.14. Simulation Result of OOK Demodulator with PLC
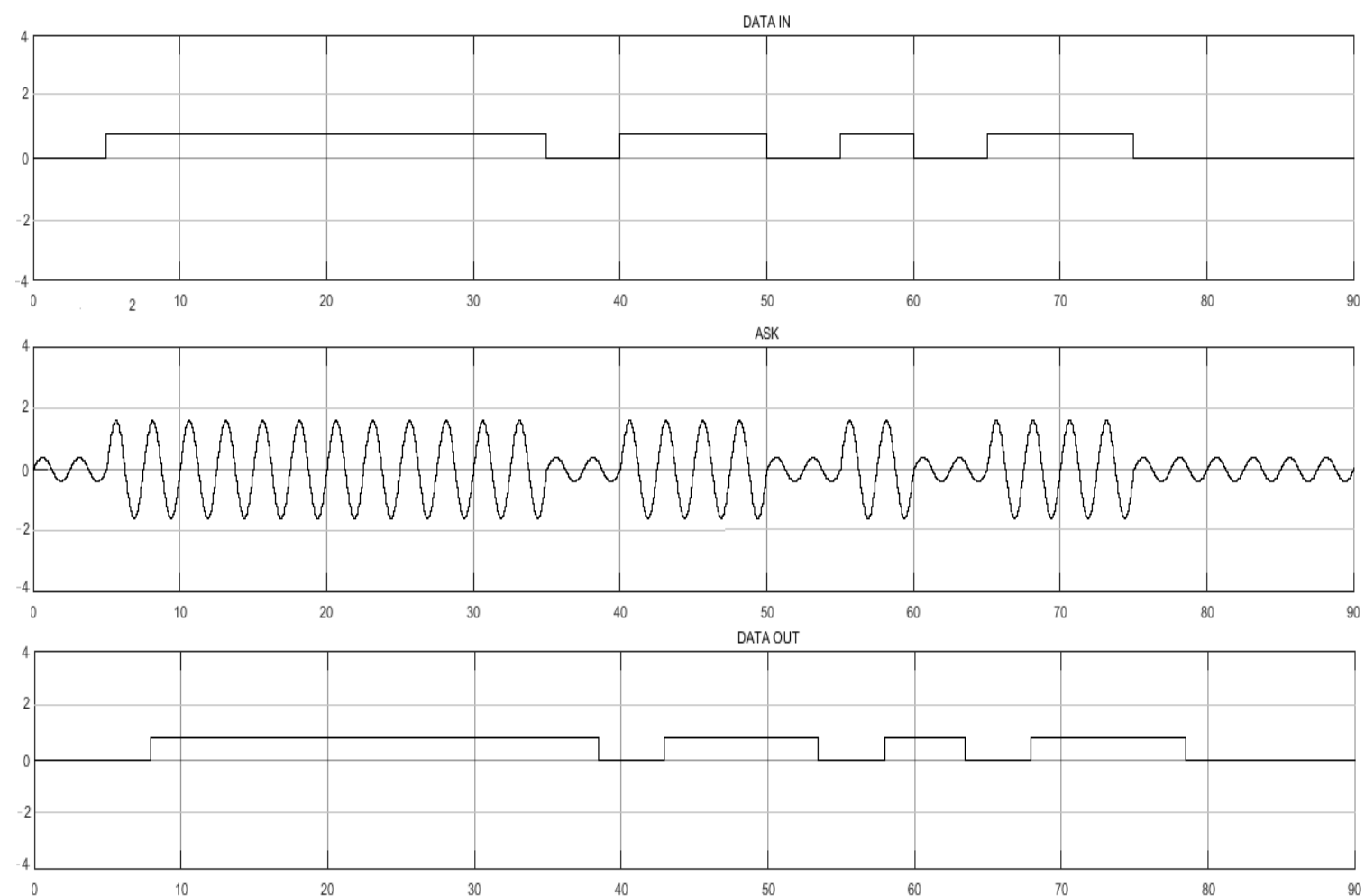

Fig.15. Data In and Data Out with ASK 

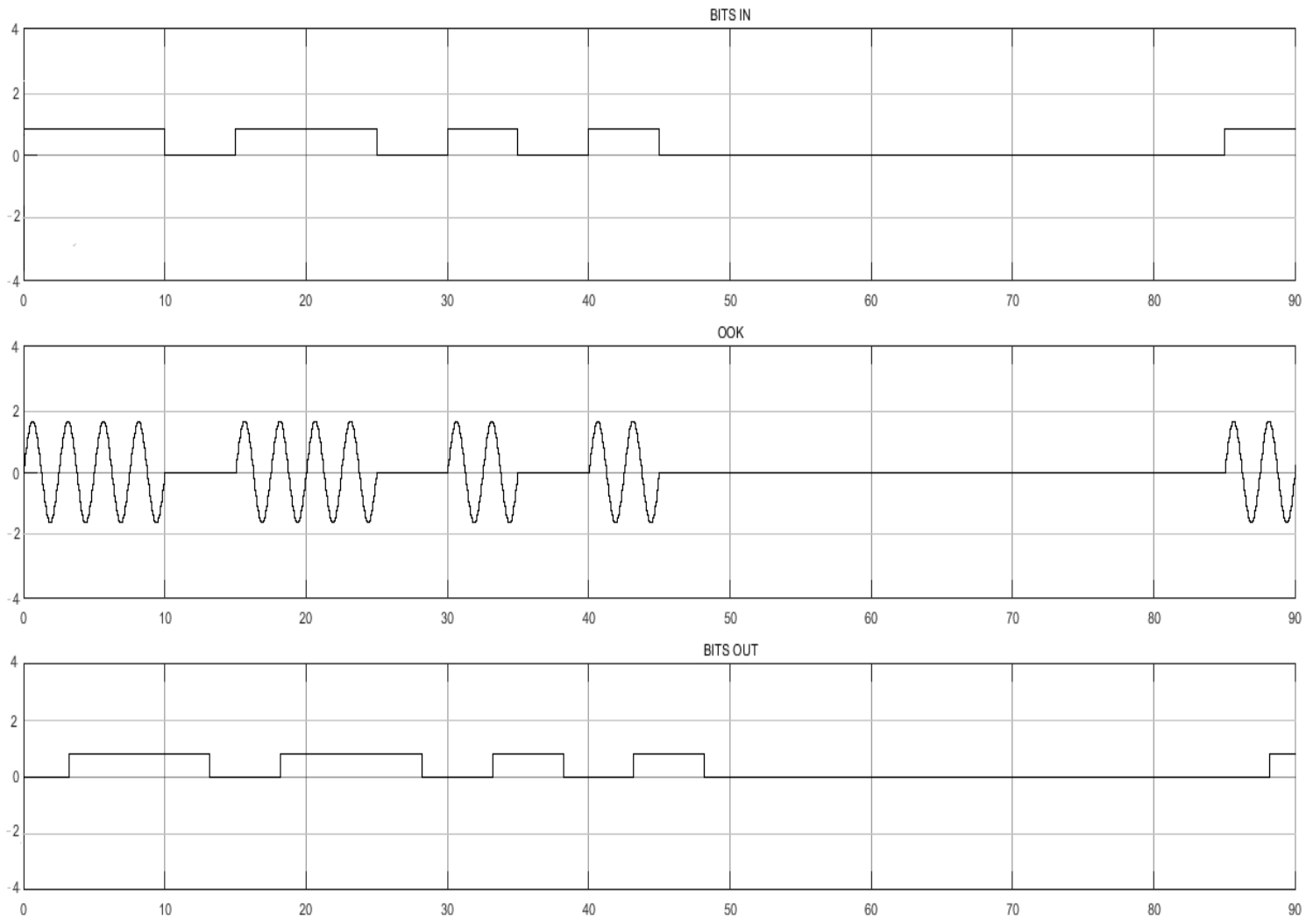

Fig.16. Data Bits In and Out with OOK

\section{CONCLUSION}

The ASK/OOK system focuses on transmitting and receiving the measure data of multiple smart meters in smart micro-grid system by using power line communication (PLC). The present ASK/OOK modem is very simple,economical and has ability to control the data transmission for smart micro-grid. It can be an excellent, cost effective and also a reliable solution to mitigation the existing power crisis, power theft and power loss if properly implements this proposed model.

\section{ACKNOWLEDGEMENT}

I express my sincere thanks to the support given by management,RIT Visakhapatnam, India, completing my work. I am thankful to the teaching and non-teaching staff of EEE department for their direct as well as indirect help in this project. I am elated to avail my selves to this opportunity to express my deep sense of gratitude to my parents and friends.

\section{REFERENCES}

[1] Guzelgoz, S. (2011). Characterizing wireless and power line communication channels with applicationsto smart grid networks. $\mathrm{PhD}$ Dissertation, University of South Florida.

[2] Clien Y Bai, H Chen and C Hung, "Home Application energy monitoring and controlling based on PLC", IEEE, ICCE, 2009.

[3] M V Aleyas1, Nishin Antony2, Sandeep T3, Sudheesh Kumar M4, Vishnu Balakrishnan5 "“Automatic Meter Reading and Load Management using Power Line Carrier Communication”IJAREEIE Trans. Vol.3, Issue5, May 2014.

[4] H. Meng, Y.Ll. Guan and S. Chen, "Modeling and Analysis of Noise Effects on Broadband Power-line Communications," IEEE Trans. Power Delivery, vol.20, pp. 630- 637, April, 2005.

[5] M. Zimmermann and K. Dostert, "Analysis and modeling of impulsive noise in broad-band power line communications," IEEE Trans. Electromagn.Compat., vol. 44, no. 1, pp. 249-258, Feb. 2002.

[6] Q. Gao, J. Y. Yu, P. H. J. Chong, P. L. So, and E. Gunawan, "Solutions for the "silent node" problem in an automatic meter reading system using power-line communications," IEEE Trans. Power Del., vol. 23, no. 1, pp. 150-156, Jan. 2008.

[7] B.Sivaneasan, E. Gunawan, and P. L. So, "Modeling and performance analysis of automatic meter-reading systems using PLC under impulsive noise interference,” IEEE Trans. Power Del., vol. 25, no. 3, pp. 1465- 1475, Jul. 2010.

[8] Elena Mainardi, Marcello Bonfe, " Power Line Communication in Home-Building Automation System.

[9] L. AlAbdulkarim and Z. Lukszo, "Impact of privacy concerns on consumers' acceptance of smart metering in the Netherlands," in Proc. IEEE Int. Conf. Netw. Sens. Control (ICNSC), Delft, The Netherlands, Apr. 2011, pp. 287-292.

[10] B V Rajanna, SVNL Lalitha, GantaJogaRao, S.K Shrivastava BPSK Modulation and Demodulation with Power Line Carrier Communication and GSM Communication for Smart Metering International Journal of Power Electronics and Drive System (IJPEDS) Vol. 7, No. 3, September 2016, pp. 713-722

[11] DrO.ChandraSekharMr B V RajannaMr M .Kiran Kumar, Automatic Meter Reading For Smart Metering By Using QPSK Modem With PLC Channel and GSM Modem, Journal of Electrical Engineering (JEE)-2015

[12] Z. Erkin, J. Troncoso-Pastoriza, R. Lagendijk, and F. Perez-Gonzalez, "Privacy- preserving data aggregation in smart metering systems: An overview,” IEEE Signal Process. Mag., vol. 30, no. 2, pp. 7586, Mar. 2013. 
[13] S. Salinas, M. Li, and P. Li, "Privacy-preserving energy theft detection in smart grids: A P2P computing approach," IEEE J. Sel. Areas Commun., vol. 31, no. 9, pp. 257-267, Sep. 2013.

[14] F. Li, B. Luo, and P. Liu, "Secure information aggregation for smart grids using homomorphic encryption,"in Proc. 1st IEEE Int. Conf. Smart Grid Commun. (SmartGridComm), Gaithersburg, MD, USA, Oct. 2010, pp. 327-332.

\section{AUTHOR PROFILE}

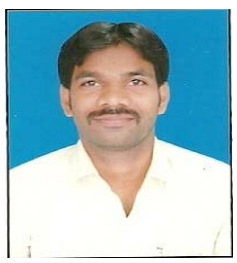

Dr. G JogaRao is working as an associate professor in the department of EEE, Raghu Iinstitute of Technology Visakhapatnam, India. He obtained his B.Tech (Electrical \& Electronics Engineering) degree from KITS, J.N.T University, Hyderabad, India, in 2004, M.Tech degree from J.N.T University College of Engineering, Hyderabad, India in 2007 and $\mathrm{Ph} . \mathrm{D}$ degree from S.R University Alwar, India in 2016. He has more than 10 years of teaching experience in various colleges in India and published more than 35 national and international journals. His area of interest includes Energy Systems, and Renewable Energy Sources, Micro Grids and Smart Grids. He is a Life Member of the Indian Society for Technical Education.

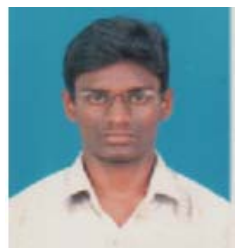

Mr. P Naresh is working as an assistant professor in the department of EEE, Raghu Engineering College, Visakhapatnam, India. He obtained his B.Tech (Electrical \& Electronics Engineering) degree from QISCET, J.N.T University, Hyderabad, India, in 2007, M.Tech degree from Andhra University College, Visakhapatnam, India in 2009. His area of interest includes Renewable Energy Sources, Micro Grids and Smart Grids.

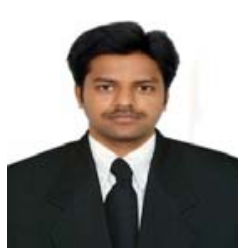

Mr. G.S.N.M Venkatesh is working as an assistant professor in the department of EEE, Raghu Institiue of Tehnology, Visakhapatnam, India. He obtained his B.Tech (Electrical \& Electronics Engineering) degree from KIET, J.N.T University, Kakinada, India, in 2009, M.Tech degree from J.N.T University, Kakinada, India, in 2013. His area of interest includes Power systems, Power Electronics, Micro Grids and Smart Grids.

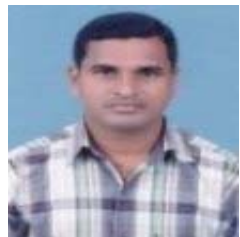

Mr. P Ramreddy is working as an assistant professor in the department of EEE, Kamala Institute of Technology and Science, Telangana, India. He obtained his B.Tech (Electrical \& Electronics Engineering) degree from KITS, J.N.T University, Hyderabad, India, in 2004, M.Tech degree from VEC, J.N.T University, Hyderabad, India in 2008. His area of interest includes Power Systems, Micro Grids and Smart Grids. 